\title{
High Correlation of 2,2-diphenyl-1-picrylhydrazyl (DPPH) Radical Scavenging, Ferric Reducing Activity Potential and Total Phenolics Content Indicates Redundancy in Use of All Three Assays to Screen for Antioxidant Activity of Extracts of Plants from the Malaysian Rainforest
}

\section{Garry Clarke ${ }^{1}$, Kang Nee Ting ${ }^{2}$, Christophe Wiart ${ }^{2}$ and Jeffrey Fry ${ }^{1, *}$}

1 School of Biomedical Sciences, University of Nottingham, Nottingham NG7 2UH, UK; E-Mail: garry.clarke@nottingham.ac.uk

2 School of Biomedical Sciences, University of Nottingham, Jalan Broga, 43500, Semenyih, Selangor, Malaysia; E-Mails: Kang-Nee.Ting@nottingham.edu.my (K.N.T.);

Christophe.Wiart@nottingham.edu.my (C.W.)

* Author to whom correspondence should be addressed; E-Mail: jeff.fry@nottingham.ac.uk; Tel.: +44-115-8230160; Fax: +44-115-8230142.

Received: 24 October 2012; in revised form: 29 November 2012 / Accepted: 20 December 2012 / Published: 4 January 2013

Abstract: Extracts of plants from the Malaysian rainforest and other fragile habitats are being researched intensively for identification of beneficial biological actions, with assessment of antioxidant behavior being a common component of such assessments. A number of tests for antioxidant behavior are used, with the 2,2-diphenyl-1-picrylhydrazyl (DPPH) and ferric reduction activity potential (FRAP) assays often being used in parallel, and also with measurement of total phenolics content (TPC) as a surrogate marker for antioxidant capacity. The present study investigated the possible redundancy in using all three assays to determine antioxidant capacity in 92 extracts obtained from 27 plants from the Malaysian rainforest. The results demonstrated that the assays displayed a high $(R \geq 0.82)$ and significant $(P<0.0001)$ correlation with one another, indicating a high level of redundancy if all three assays are used in parallel. This appears to be a waste of potentially valuable plant extracts. Because of problems with the FRAP assay relating to color interference and variable rates of reaction point, the DPPH assay is the preferred assay in preliminary screening of extracts of plants from the Malaysian rainforest. 
Keywords: antioxidant; plant extracts; DPPH; FRAP; phenolics; correlation

\section{Introduction}

There is considerable interest in charting the biological activities of plants from geographically remote and fragile habitats such as the primary rainforests of Malaysia and other locations in South-East Asia, in the hope of identifying novel compounds of potential therapeutic value [1].

Oxidative stress is believed to be a major contributor to the pathogenesis of a number of chronic diseases [2], and it is for this reason that antioxidant behavior is one of the most commonly determined biological activities in extracts of plants [3]. A wide variety of antioxidant assays are used when determining the antioxidant activity of plant extracts, two common ones being based on the scavenging of the DPPH (2,2-diphenyl-1-picrylhydrazyl) radical (DPPH assay) and ferric reduction activity potential (FRAP assay). Many utilize both the DPPH and the FRAP assays in their plant activity screening programs, presumably on the assumption that a combination of the data would provide a better description of antioxidant activity than obtained from a single assay (for recent examples see [4-7]). However, should this assumption not be correct, use of these two assays will use up potentially valuable plant material without providing additional information.

As part of a program mapping the biological activities of plants of the Malaysian rainforest, a total of 96 extracts isolated from 27 plants have been tested using both the DPPH and FRAP assays, and an assessment made of the correlation between the two assays. These findings are presented in this paper, together with data on the total phenolics content (TPC) of the extracts, which is often taken as an indirect measure of antioxidant capacity [8].

\section{Experimental Section}

\subsection{Collection of Plants and Preparation of Extracts}

Plant extracts were collected from various sites in the Malaysian primary rainforest, with relevant authority as required under the framework of the United Nations Convention on Biodiversity, and water (W), ethanol (EtOH), ethyl acetate (EtAc) and hexane (Hex) fractions were prepared from leaf, bark or the whole aerial parts of the plant using standard techniques [9]. A full listing of the plants and extracts is given in Table 1.

Table 1. Plant extracts used in this study and their antioxidant activity as determined by results of the 2,2-diphenyl-1-picrylhydrazyl (DPPH), ferric reduction activity potential (FRAP) and total phenolics content (TPC) assays.

\begin{tabular}{ccccccc}
\hline $\begin{array}{c}\text { Extract } \\
\text { No. }\end{array}$ & Plant & Part & Extract & DPPH $^{\mathbf{1}}$ & FRAP $^{\mathbf{1}}$ & TPC $^{\mathbf{2}}$ \\
\hline 1 & Apama tricornutum & Leaf & EtOH & 2740 & 1617 & 59.6 \\
2 & & EtAc & $\geq 4000$ & $\geq 4000$ & 37.2 \\
3 & & & Hex & $\geq 4000$ & $\geq 4000$ & 9.0 \\
\hline
\end{tabular}


Table 1. Cont.

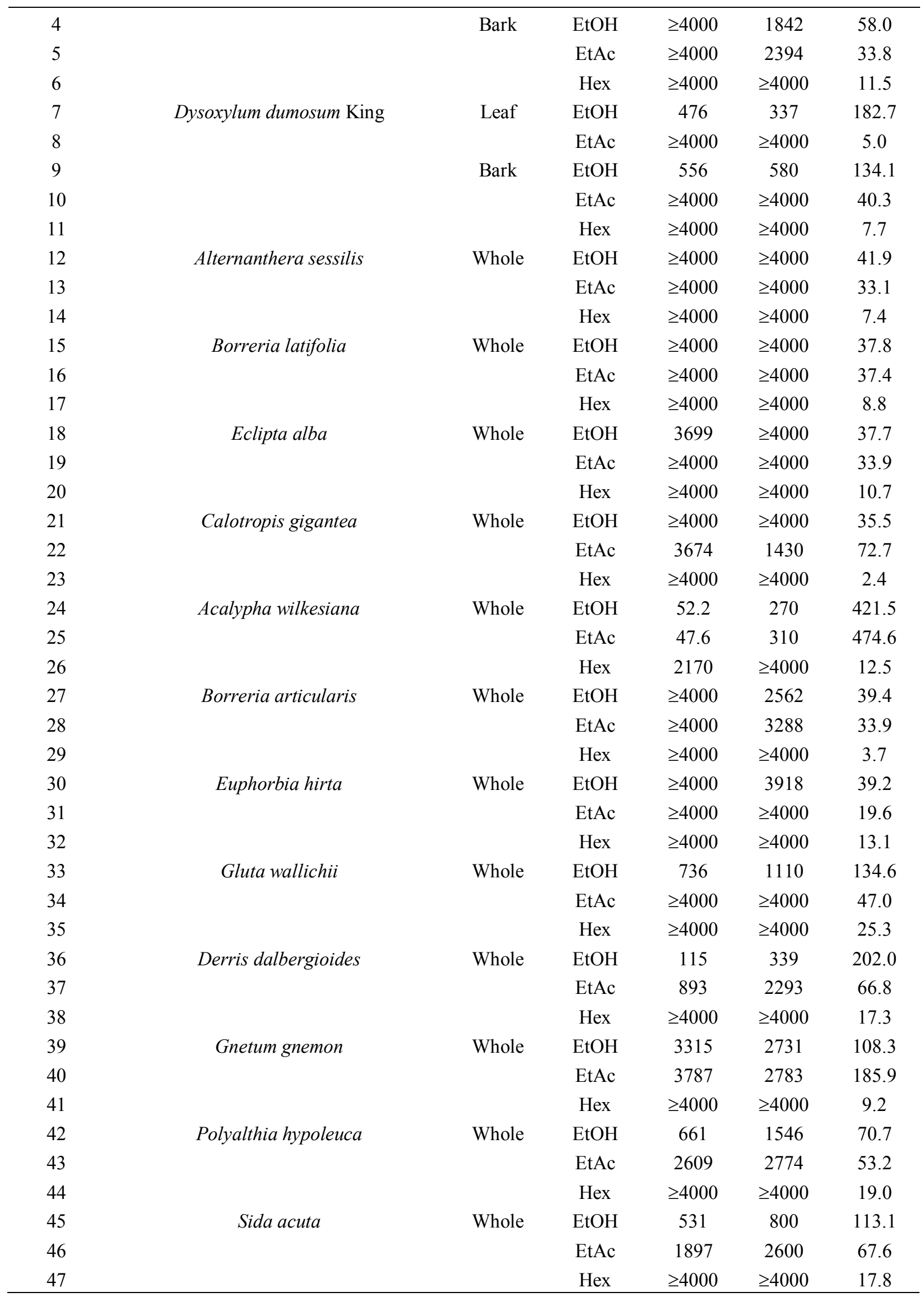


Table 1. Cont.

\begin{tabular}{|c|c|c|c|c|c|c|}
\hline 48 & Pseudo-uvaria macrophylla (Oliv.) Merr. & Whole & $\mathrm{EtOH}$ & 431 & 1260 & 91.9 \\
\hline 49 & & & EtAc & $\geq 4000$ & $\geq 4000$ & 30.1 \\
\hline 50 & & & Hex & $\geq 4000$ & $\geq 4000$ & 14.3 \\
\hline 51 & Berberis thunbergii & Whole & $\mathrm{EtOH}$ & $\geq 4000$ & 2553 & 78.5 \\
\hline 52 & & & EtAc & $\geq 4000$ & $\geq 4000$ & 36.9 \\
\hline 53 & & & Hex & $\geq 4000$ & $\geq 4000$ & 13.6 \\
\hline 54 & Ipomoea quamoclit & Whole & EtOH & 3460 & $\geq 4000$ & 24.1 \\
\hline 55 & & & EtAc & 3210 & $\geq 4000$ & 42.3 \\
\hline 56 & Oldenlandia corymbosa $\mathrm{L}$. & Whole & $\mathrm{EtOH}$ & 3740 & $\geq 4000$ & 35.6 \\
\hline 57 & & & EtAc & $\geq 4000$ & $\geq 4000$ & 15.3 \\
\hline 58 & & & Hex & $\geq 4000$ & $\geq 4000$ & 8.6 \\
\hline 59 & Bidens pilosa $\mathrm{L}$. & Whole & EtOH & 720 & 730 & 83.4 \\
\hline 60 & & & EtAc & 900 & 900 & 105.0 \\
\hline 61 & Justicia betonica L. & Whole & $\mathrm{EtOH}$ & $\geq 4000$ & 3040 & 28.6 \\
\hline 62 & & & EtAc & $\geq 4000$ & $\geq 4000$ & 40.1 \\
\hline 63 & & & Hex & $\geq 4000$ & $\geq 4000$ & 6.5 \\
\hline 64 & Clerodendrum paniculatum & Whole & $\mathrm{EtOH}$ & 1720 & 2300 & 71.7 \\
\hline 65 & & & EtAc & 3190 & $\geq 4000$ & 34.5 \\
\hline 66 & & & Hex & $\geq 4000$ & $\geq 4000$ & 6.1 \\
\hline 67 & Ardisia punctata Jack & Whole & $\mathrm{EtOH}$ & 710 & 810 & 101.7 \\
\hline 68 & & & EtAc & 1310 & 3130 & 83.8 \\
\hline 69 & & & Hex & 2460 & $\geq 4000$ & 78.0 \\
\hline 70 & Clerodendron nutans Jack & Whole & $\mathrm{EtOH}$ & 1000 & 1040 & 67.1 \\
\hline 71 & & & EtAc & 1320 & 1990 & 56.4 \\
\hline 72 & & & Hex & $\geq 4000$ & $\geq 4000$ & 9.2 \\
\hline 73 & Marsypopetallum pallidum (B1.) Kurz & Leaf & Water & 420 & 710 & 128.3 \\
\hline 74 & & & EtOH & 1530 & 1380 & 76.9 \\
\hline 75 & & & EtAc & $\geq 4000$ & $\geq 4000$ & 19.2 \\
\hline 76 & & & Hex & $\geq 4000$ & $\geq 4000$ & 16.7 \\
\hline 77 & Archidendron ellipticum & Leaf & $\mathrm{EtOH}$ & 1310 & 1130 & 97.3 \\
\hline 78 & & & EtAc & 1930 & 2420 & 60.0 \\
\hline 79 & & & Hex & $\geq 4000$ & $\geq 4000$ & 8.6 \\
\hline 80 & & Bark & $\mathrm{EtOH}$ & 1970 & 2310 & 32.3 \\
\hline 81 & & & EtAc & $\geq 4000$ & $\geq 4000$ & 25.0 \\
\hline 82 & & & Hex & $\geq 4000$ & $\geq 4000$ & 9.8 \\
\hline 83 & Pipturus argenteus (Forst. f.) & Leaf & $\mathrm{EtOH}$ & 340 & 940 & 119.2 \\
\hline 84 & & & EtAc & 3520 & $\geq 4000$ & 19.3 \\
\hline 85 & & & Hex & $\geq 4000$ & $\geq 4000$ & 12.0 \\
\hline 86 & & Bark & $\mathrm{EtOH}$ & 540 & 550 & 174.6 \\
\hline 87 & & & EtAc & $\geq 4000$ & $\geq 4000$ & 28.7 \\
\hline 88 & & & Hex & $\geq 4000$ & $\geq 4000$ & 6.4 \\
\hline 89 & Duabanga grandiflora & Leaf & Water & 140 & 210 & 251.9 \\
\hline 90 & & & $\mathrm{EtOH}$ & 50.0 & 110 & 476.8 \\
\hline 91 & & & EtAc & 150 & 280 & 192.3 \\
\hline 92 & & & Hex & $\geq 4000$ & $\geq 4000$ & 10.4 \\
\hline
\end{tabular}


Table 1. Cont.

\begin{tabular}{|c|c|c|c|c|c|c|}
\hline 93 & & Bark & Water & 130 & 260 & 363.7 \\
\hline 94 & & & $\mathrm{EtOH}$ & 80.0 & 210 & 404.6 \\
\hline 95 & & & EtAc & 240 & 570 & 135.4 \\
\hline \multirow[t]{2}{*}{96} & & & Hex & $\geq 4000$ & $\geq 4000$ & 18.9 \\
\hline & Quercetin & & & $\begin{array}{l}59.8 \pm \\
0.75^{3}\end{array}$ & $\begin{array}{c}49.9 \pm \\
1.02^{3}\end{array}$ & N/A \\
\hline
\end{tabular}

\footnotetext{
${ }^{1}$ Activity measured as $\mathrm{EC}_{50}(\mu \mathrm{g} / \mathrm{mL})$ for DPPH assay or $\mathrm{FE}(\mu \mathrm{g} / \mathrm{mL})$ for FRAP assay.

${ }^{2}$ Content measured as $\mu \mathrm{g}$ quercetin equivalents per $\mathrm{mg}$ of extract.

${ }^{3} \operatorname{Mean} \pm \operatorname{SEM}(n=5-6)$.
}

\subsection{Chemicals}

DPPH, DMSO, quercetin, tripyridyltriazine (TPTZ) and Folin-Ciocalteau (F-C) reagent were obtained from Sigma-Aldrich, Dorset, UK. All other chemicals were of the highest analytical grade available from local suppliers.

\subsection{DPPH Assay}

For the DPPH radical scavenging assay, $20 \mu \mathrm{L}$ of extract diluted appropriately in DMSO was mixed with $180 \mu \mathrm{L}$ of DPPH in methanol $(40 \mu \mathrm{g} / \mathrm{mL})$ in wells of a 96 -well plate. The plate was kept in the dark for $15 \mathrm{~min}$, after which the absorbance of the solution was measured at $540 \mathrm{~nm}$ in a Multiskan Ascent plate-reader (Thermo Electron Corporation, Basingstoke, UK). Appropriate blanks (DMSO) and standards (quercetin solutions in DMSO) were run simultaneously. Extracts were first tested at a single concentration of $4 \mathrm{mg} / \mathrm{mL}$, and those showing good evidence of antioxidant activity were tested over a range of concentrations to establish the $\mathrm{EC}_{50}$ (the concentration reducing DPPH absorbance by $50 \%$ ). This method follows closely that used by previous workers [4-7].

\subsection{FRAP Assay}

For determination of FRAP response, $20 \mu \mathrm{L}$ of extract diluted appropriately in DMSO was mixed with $180 \mu \mathrm{L}$ FRAP reagent in wells of a 96-well plate, left for 6 minutes, and the absorbance measured at $595 \mathrm{~nm}$ in a Multiskan Ascent plate-reader. FRAP reagent was prepared freshly by mixing $300 \mathrm{mM}$ acetate buffer $\mathrm{pH} 3.6,10 \mathrm{mM}$ TPTZ in $40 \mathrm{mM} \mathrm{HCl}$, and $20 \mathrm{mM} \mathrm{FeCl} 3.6 \mathrm{H}_{2} 0$ in the volume ratio 10:1:1. Appropriate blanks of plant extract and of FRAP reagent lacking TPTZ (to correct for color of the extracts) were run, together with quercetin (in DMSO) and $\mathrm{FeSO}_{4}$ as a standard. FRAP activity was calculated as Ferrous Equivalents (FE), the concentration of extract/quercetin which produced an absorbance value equal to that of $1 \mathrm{mM} \mathrm{FeSO}_{4}$. Once again, extracts were first tested at a single concentration of $4 \mathrm{mg} / \mathrm{mL}$, and those showing good evidence of antioxidant activity were tested over a range of concentrations to establish the FE. This method follows closely that used by previous workers [4-7]. 


\subsection{TPC Assay}

The total phenolics content of the extracts was determined by reaction with F-C reagent. Thus, $10 \mu \mathrm{L}$ of extract diluted appropriately in DMSO was mixed with $100 \mu \mathrm{L}$ F-C reagent freshly diluted $1 / 10$ with distilled water. After five minutes, the solution was mixed with $100 \mu \mathrm{L} 7.5 \% \mathrm{Na}_{2} \mathrm{CO}_{3}$ solution, and the whole left for $60 \mathrm{~min}$, before measurement of absorbance at $650 \mathrm{~nm}$ in a Multiskan Ascent plate-reader. Appropriate blanks (DMSO) and standard (quercetin in DMSO) were run simultaneously, after which the total phenolics content was calculated as $\mu$ g quercetin equivalents per mg extract. This method follows closely that used by previous workers [4-7].

\subsection{Data Analysis}

Correlation and regression analysis of the data were performed using the GraphPad Prism v4 program.

\section{Results and Discussion}

\subsection{Results}

The results from the DPPH, FRAP, and TPC assays are presented in Table 1. Of the 96 extracts tested, many were inactive in both of the antioxidant assays $\left(\mathrm{EC}_{50}\right.$ or $\mathrm{FE}$ greater than $4000 \mu \mathrm{g} / \mathrm{mL}$ ). Nevertheless, non-parametric Spearman correlation analysis of all 96 data points demonstrated highly significant $(P<0.0001)$ positive correlation between the DPPH and FRAP results $(R=0.852)$. When the extracts for which both DPPH and FRAP values were greater than $4000 \mu \mathrm{g} / \mathrm{mL}$ were excluded, the remaining 36 extracts still displayed a highly significant correlation (Spearman $R=0.889$ ). This is exemplified in Figure 1, in which the $\log _{10}$ values for these 36 extracts are plotted, linear regression yielding the following equation:

$$
\log _{10} \mathrm{FRAP}=0.6484 \log _{10} \mathrm{DPPH}+0.8440\left(R^{2}=0.8162 ; P<0.0001\right)
$$

Figure 1. Correlation of DPPH value (as $\mathrm{EC}_{50}$ in $\mu \mathrm{g} / \mathrm{mL}$ ) and FRAP value (as FE in $\mu \mathrm{g} / \mathrm{mL}$ ) for the 36 plant extracts indicated in Table 1 with $\mathrm{EC}_{50}$ and FE values of less than $4000 \mu \mathrm{g} / \mathrm{mL}$, presented on $\log _{10}$ scales.

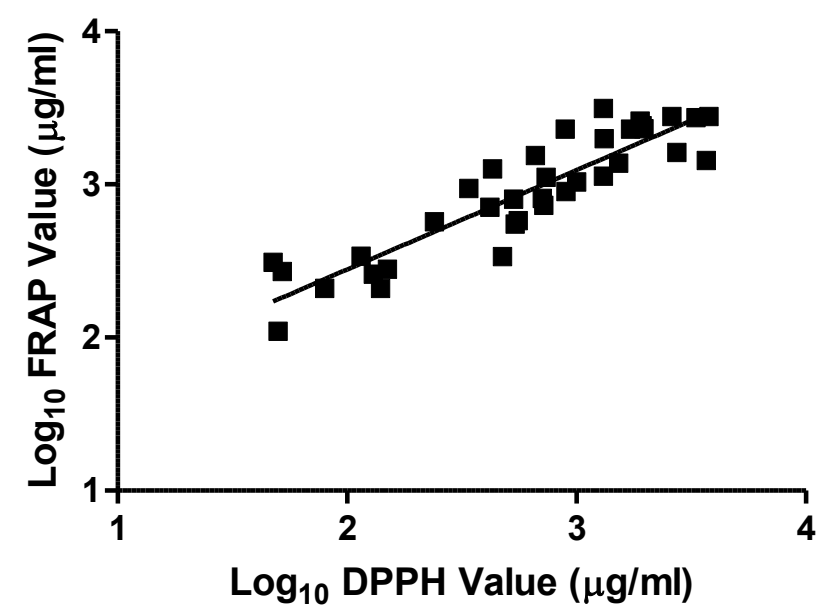


There was also a highly significant $(P<0.0001)$ negative correlation between the DPPH/FRAP and TPC values for all 96 extracts (Spearman $R$ for DPPH $=-0.821$ and for FRAP $=-0.848$ ). In general, those extracts for which the results of one or both of the DPPH and FRAP assays yielded $\mathrm{EC}_{50} / \mathrm{FE}$ values greater than $4000 \mu \mathrm{g} / \mathrm{mL}$ possessed a TPC value of approximately $55 \mu \mathrm{g}$ quercetin equivalents per $\mathrm{mg}$ extract or less. For those extracts displaying $\mathrm{EC}_{50} / \mathrm{FE}$ values less than $4000 \mu \mathrm{g} / \mathrm{mL}$, a curvilinear relationship of DPPH/FRAP against TPC was apparent (see Figure 2 for FRAP data), with extracts displaying a TPC in excess of $200 \mu \mathrm{g}$ quercetin equivalents per mg extract also displaying high antioxidant activity by either DPPH or FRAP assay. One possible outlier is extract 40 (open diamond symbol in Figure 2); the reason for this remains to be determined.

Figure 2. Relation between FRAP value (as FE in $\mu \mathrm{g} / \mathrm{mL}$ ) and TPC (as $\mu \mathrm{g}$ quercetin equivalents/mg extract) for the 36 plant extracts indicated in Table 1 with FE value less than $4000 \mu \mathrm{g} / \mathrm{mL}$.

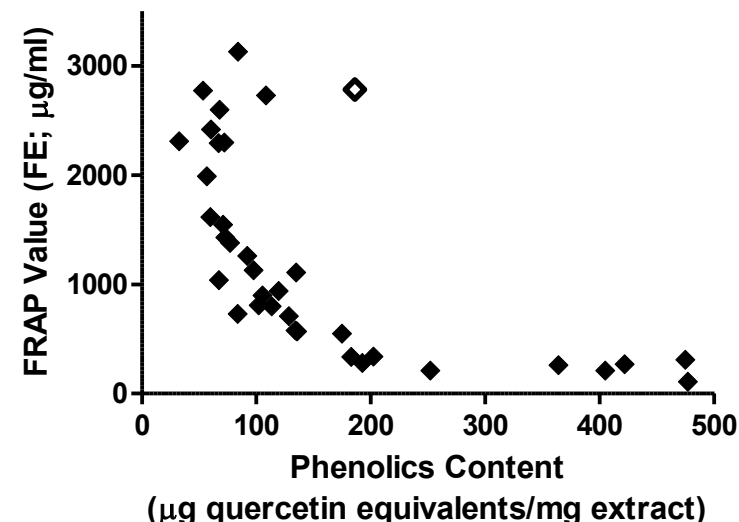

Two methodological problems became apparent during the early stages of performing the FRAP assays. The first problem to emerge was that the color of some of the extracts interfered in the assay, and "color controls" (FRAP reagent in which the TPTZ solution was replaced with an equal volume of $40 \mathrm{mM} \mathrm{HCl}$ ) had to be introduced; this did not appear to be a major issue with the DPPH assay. The second problem to emerge was that, for some extracts, the color reaction was not complete within the 6-min assay period; an example is shown in Figure 3.

Figure 3. Concentration dependence for FRAP reaction of plant extract 2, measured after incubation for $6 \mathrm{~min}(\boldsymbol{\square})$ or $3 \mathrm{~h}(\boldsymbol{\Delta})$.

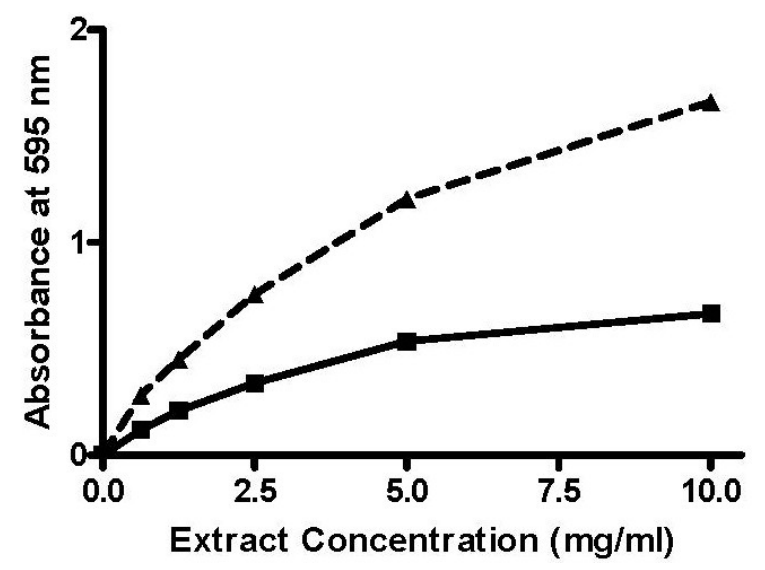




\subsection{Discussion}

The results of this investigation have demonstrated that screening for antioxidant activity of extracts of plants from the Malaysian rainforest by DPPH and FRAP assays gives essentially identical results. In addition, it was apparent that extracts displaying good antioxidant behavior in both the DPPH and FRAP assays could be identified by high phenolics content, and that methodological issues with the FRAP assay may potentially compromise the usefulness of this assay when testing plant extracts.

The finding that the results of the DPPH and FRAP assays for plant extracts were highly correlated agrees with the work of others (for examples, see $[4,10,11]$ ), and is consistent with the view that the two assays share a similar mechanistic basis, viz. transfer of electrons from the antioxidant to reduce an oxidant, as proposed by Huang, Ou and Prior [8]. A number of papers have reported results from both DPPH and FRAP (or other $\mathrm{Fe}^{3+}$-reduction) assays on plant extracts (see [4-7]), presumably in the belief that using two assays improves the overall estimate of antioxidant capacity of the plant extracts, and/or that each assay reflects a different aspect of the antioxidant behavior of a plant extract. However, the results from the present and previous studies, together with the similar mechanistic basis of the assays, suggest a high degree of redundancy in use of both assays for screening plant extracts.

Under these circumstances, a decision needs to be made as to which assay to use to screen for antioxidant activity, so as to reduce the use of potentially valuable plant extracts. In the work reported here, two problems were identified with the use of the FRAP assay-interference caused by the color in some extracts, and slow development of color. The former was possibly due to the acid $\mathrm{pH}$ under which the FRAP assay was run, and was much less of a problem with the DPPH assay. The slow development of color has been reported in other studies [12-14], and has been taken to indicate the involvement of multiple antioxidants in the observed response, each acting under different kinetic conditions. Although similar issues have been reported for the DPPH assay [13,14], this did not appear to be a major problem in the studies reported here or in subsequent studies with other plant extracts [15].

The TPC assay is another assay that is commonly used in conjunction with either or both of the DPPH and FRAP assays, again presumably with the aim of increasing the information database on a particular plant extract. The results presented in this study indicate that high antioxidant activity is associated with a high phenolics content, a finding reported previously many times (for recent examples see $[4,6,10,16])$, so it could be argued that the only virtue in performing the TPC assay would be as a screen to evaluate extracts further by either the DPPH or FRAP assays. Under such circumstances, the critical point would then become the threshold value above which further screening would be undertaken. This value will obviously depend upon the standard being used for the TPC assay, but under the present experimental conditions, this threshold value would appear to be $200 \mu \mathrm{g}$ quercetin equivalents per mg extract.

It should be noted that the assays used in this work represent only a few of the many antioxidant assays available (see review by Huang, Ou and Prior [8]), albeit three of the most popular in studies of antioxidant capacity of plant extracts, as exemplified by examples referenced above. 


\section{Conclusions}

In conclusion, this study has indicated that results of the DPPH, FRAP and TPC assays provide essentially identical information in regard to the antioxidant capability of extracts of plants from the Malaysian rainforest, so that it is difficult to establish what additional information could be gained by use of more than one of the three assays employed in this study. Given this level of redundancy with these assays, two screening scenarios can be proposed-screening of all extracts by DPPH assay or determination of TPC followed by more detailed analysis by DPPH assay for those extracts demonstrating a total phenolics content of $200 \mu \mathrm{g}$ quercetin equivalents per mg extract or more. The former approach is currently being used in characterization of other extracts of plants from the Malaysian rainforest.

\section{References}

1. Ting, K.N.; Othman, M.; Telford, G.; Clarke, G.; Bradshaw, T.D.; Khoo, T.J.; Loh, H.S.; Wiart, C.; Pritchard, D.; Fry, J.R. Antioxidant, cytoprotective, growth inhibitory and immunomodulatory activities of extracts of Dysoxylum cauliflorum Hiern., a Malaysian Meliaceae. J. Med. Plants Res. 2011, 5, 5867-5872.

2. Ames, B.N.; Shigenaga, M.K.; Hagen, T.M. Oxidants, antioxidants, and the degenerative diseases of aging. Proc. Nat. Acad. Sci. USA 1993, 90, 7915-7922.

3. Duthie, G.G.; Duthie, S.J.; Kyle, J.A.M. Plant polyphenols in cancer and heart disease: Implications as nutritional antioxidants. Nutr. Res. Rev. 2000, 13, 79-106.

4. Dudonné, S.; Vitrac, X.; Coutière, P.; Woillez, M.; Mérillon, J.-M. Comparative study of antioxidant properties and total phenolic content of 30 plant extracts of industrial interest using DPPH, ABTS, FRAP, SOD, and ORAC assays. J. Agric. Food Chem. 2009, 57, 1768-1774.

5. Zhang, H.; Jiang, L.; Ye, S.; Ye, Y.; Ren, F. Systematic evaluation of antioxidant capacities of the ethanolic extract of different tissues of jujube (Ziziphus jujuba Mill.) from China. Food Chem. Toxicol. 2010, 48, 1461-1465.

6. Qader, S.W.; Abdulla, M.A.; Chua, L.S.; Najim, N.; Zain, M.M.; Hamdan, S. Antioxidant, total phenolic content and cytotoxicity evaluation of selected Malaysian plants. Molecules 2011, 16, 3433-3443.

7. Tai, Z.; Cai, L.; Dai, L.; Dong, L.; Wang, M.; Yang, Y.; Cao, Q.; Ding, Z. Antioxidant activity and chemical constituents of edible flower of Sophora viciifolia. Food Chem. 2011, 126, 1648-1654.

8. Huang, D.; Ou, B.; Prior, R.L. The chemistry behind antioxidant capacity assays. J. Agric. Food Chem. 2005, 54, 1841-1856

9. Othman, M.; Loh, H.S.; Wiart, C.; Khoo, T.J.; Lim, K.H.; Ting, K.N. Optimal methods for evaluating antimicrobial activities from plant extracts. J. Microbiol. Methods 2011, 84, 161-166.

10. Xu, H.-X.; Chen, J.-W. Commercial quality, major bioactive compound content and antioxidant capacity of 12 cultivars of loquat (Eriobotrya japonica Lindl.) fruits. J. Sci. Food Agric. 2011, 91, 1057-1063. 
11. Szydłowska-Czerniak, A.; Bartkowiak-Broda, I.; Karlović, I.; Karlovits, G.; Szłyk, E. Antioxidant capacity, total phenolics, glucosinolates and colour parameters of rapeseed cultivars. Food Chem. 2011, 127, 556-563.

12. Halvorsen, B.L.; Blomhoff, R. Validation of a quantitative assay for the total content of lipophilic and hydrophilic antioxidants in foods. Food Chem. 2011, 127, 761-768.

13. Ozgen, M.; Reese, R.N.; Tulio, A.Z., Jr.; Scheerens, J.C.; Miller, A.R. Modified 2,2-azino-bis-3ethylbenzothiazoline-6-sulfonic acid (ABTS) method to measure antioxidant capacity of selected small fruits and comparison to ferric reducing antioxidant power (FRAP) and 2,2'-diphenyl-1picrylhydrazyl (DPPH) methods. J. Agric. Food Chem. 2006, 54, 1151-1157.

14. Stratil, P.; Klejdus, B.; Kuban, V. Determination of total content of phenlic compounds and their antioxidant activity in vegetables - Evaluation of spectrophotometric methods. J. Agric. Food Chem. 2006, 54, 607-616.

15. Clarke, G.; Fry, J.R. University of Nottingham, Nottingham, UK. Unpublished work, 2011.

16. Zhang, R.F.; Zhang, F.X.; Zhang, M.W.; Wei, Z.C.; Yang, C.Y.; Zhang, Y.; Tang, X.J.; Deng, Y.Y.; Chi, J.W. Phenolic composition and antioxidant activity in seed coats of 60 Chinese black soybean (Glycine max L. Merr.) varieties. J. Agric. Food Chem. 2011, 59, 5935-5944.

(C) 2013 by the authors; licensee MDPI, Basel, Switzerland. This article is an open access article distributed under the terms and conditions of the Creative Commons Attribution license (http://creativecommons.org/licenses/by/3.0/). 